\title{
Pulmonary Hypertension in Patients with Chronic Obstructive Pulmonary Disease: A Review for Definition, Epidemiology, Pathology, and Diagnosis
}

Oyku Gulmez*

Department of Cardiology, Baskent University, Istanbul Medical and Research Center, Istanbul, Turkey

*Corresponding author: Oyku Gulmez, Department of Cardiology, University Istanbul Medical and Research Center, Oymacı, Altunizade, Istanbul, Turkey, Tel: +90 5352496139; Fax: +902616519858; E-mail: gulmezoyku@yahoo.com

Rec date: July 17, 2017; Acc date: July 28, 2017; Pub date: July 31, 2017

Copyright: @ 2017 Gulmez O. This is an open-access article distributed under the terms of the Creative Commons Attribution License, which permits unrestricted use, distribution, and reproduction in any medium, provided the original author and source are credited

\begin{abstract}
Chronic obstructive pulmonary disease (COPD) is a type of obstructive lung disease characterized by progressive and persistent restriction of airflow with a prevalence of $19-25 \%$. The main symptoms are shortness of breath, cough, and sputum production. Smoking is the most common cause and quitting smoking is the only action which prevents developing and progressing of COPD.

Pulmonary hypertension (PHT) which is defined as a mean pulmonary artery pressure of $\geq 25 \mathrm{mmHg}$ measured by right heart catheterization at rest is a common complication of COPD and it has been investigated under the title of "Class III: Pulmonary Hypertension due to Pulmonary Disease and/or Hypoxia" according to the updated clinical classification in the $5^{\text {th }}$ World Pulmonary Hypertension Symposium. Although pathogenesis is complex, it often involves HPV and pulmonary vascular remodeling. In this review, the PHT which mainly develops secondary to COPD is discussed.
\end{abstract}

Keywords: Pulmonary hypertension; Pulmonary artery hypertension; Chronic obstructive pulmonary disease; Chronic lung disease; Pulmonary heart disease

\section{Introduction}

Chronic obstructive pulmonary disease (COPD) is a medical condition characterized by progressive and persistent restriction of airflow, and is associated with an increased chronic inflammatory response of airways to harmful gases and particulates [1]. The prevalence over the age of 40 is $19-25 \%[2,3]$.

Pulmonary damage due to COPD is irreversible. However, quitting smoking is the only action which prevents developing and progressing of COPD [1-4]. The main goal of lifestyle changes according to clinical and functional status, training, drug therapy, pulmonary rehabilitation, long-term oxygen therapy, noninvasive mechanical ventilation and bronchoscopic/surgical interventions is to reduce the symptoms and future risks $[1,4]$.

Pulmonary hypertension (PHT) which is a common complication of COPD, is determinant for the prognosis of COPD, and is estimated to be the leading fourth cause of death by $2030[5,6]$.

PHT secondary to COPD has been investigated under the title of "Class III: Pulmonary Hypertension due to Pulmonary Disease and/or Hypoxia" according to the updated clinical classification in the $5^{\text {th }}$ World Pulmonary Hypertension Symposium in Nice, France, in 2013 [7].

This group also includes diseases/conditions causing to PHT such as interstitial lung diseases, alveolar hypoventilation disorders, sleep related breathing disorders and chronic exposure to high altitude. In this review, the PHT which mainly develops secondary to COPD is discussed (Table 1).

\section{Methodology}

The initial search was conducted using Pubmed with the key words " pulmonary hypertension; pulmonary artery hypertension, chronic obstructive pulmonary disease, chronic lung disease, pulmonary heart disease".

All abstracts were assessed for relevance and articles of relevant studies were retrieved. Subsequent searches utilized the following combinations of subject's headings: classification, pulmonary circulation, pulmonary vascular resistance, hypoxia, inflammation, pulmonary vascular remodeling, diagnosis, right heart catheterization.

For relevant titles, the abstracts were reviewed and, if still relevant, the article was retrieved. References within the selected articles, especially for review articles, were also reviewed for their relevance.

\section{Definition}

In the previous consensus statement of the European Society of Cardiology and Respiratory Society published in 2009 and 2015, it was stated that the mean pulmonary artery pressure (PAP) at rest was $14 \pm$ $3 \mathrm{mmHg}$ and the upper limit was about $20 \mathrm{mmHg}[8,9]$. A mean PAP of $\geq 25 \mathrm{~mm} \mathrm{Hg}$ measured by right heart catheterization at rest is defined as PHT [9].

In people with pulmonary disease and/or hypoxemia, the precapillary PHT is defined as pulmonary capillary wedge pressure (PCWP) $\leq 15 \mathrm{mmHg}$, additionally. Although the importance of a mean PAP of 21-24 mmHg is not clear, morbidity and mortality have been shown to increase in older studies in which the mean PAP of the PHT was $>20 \mathrm{mmHg}$ [10-12]. 
Citation: Gulmez O (2017) Pulmonary Hypertension in Patients with Chronic Obstructive Pulmonary Disease: A Review for Definition, Epidemiology, Pathology, and Diagnosis. Gen Med (Los Angeles) 5: 293. doi:10.4172/2327-5146.1000293

Page 2 of 10

\begin{tabular}{|c|c|}
\hline Definition & $\begin{array}{l}\text { A mean PAP of } \geq 25 \mathrm{mmHg} \text { measured by right heart catheterization at rest is defined as PHT. } \\
\text { In people with pulmonary disease and/or hypoxemia, the pre-capillary PHT is defined as pulmonary capillary wedge pressure } \leq 15 \mathrm{mmHg} \text {, } \\
\text { additionally } \\
\text { Although the importance of a mean PAP of } 21-24 \mathrm{mmHg} \text { is not clear, morbidity and mortality have been shown to increase in older studies } \\
\text { in which the mean PAP of the PHT was }>20 \mathrm{mmHg} \\
\text { The definition of PHT in the setting of chronic lung disease is: } \\
\text { 1. Non-PHT COPD/IPF/CPFA (mean PAP }<25 \mathrm{mmHg} \text { ), } \\
\text { 2. COPD/IPF/CPFA with PHT (mean PAP } \geq 25 \mathrm{mmHg} \text { ), } \\
\text { 3. COPD/PF/CPFA with severe PHT (mean PAP } \geq 35 \mathrm{mmHg} \text { or mean cardiac index with a mean PAP } \geq 25 \mathrm{mmHg}\left(<2.0 \mathrm{~L} / \mathrm{min} / \mathrm{m}^{2} \text { ). }\right. \\
\text { The definition of severe PHT is (at least two of the criteria must be met): } \\
\text { i) mean PAP>35 } \mathrm{mmHg} \text {, } \\
\text { ii) mean PAP } \geq 25 \mathrm{mmHg} \text { and limited cardiac output }\left(\mathrm{Cl}<2.01 / \mathrm{min} / \mathrm{m}^{2} \text { ), or }\right. \\
\text { iii) pulmonary vascular resistance }(\mathrm{PVR})>480 \text { dyns } \mathrm{cm}-5\end{array}$ \\
\hline $\begin{array}{l}\text { Pathogenesis } \\
\text { Pathophysiology }\end{array}$ & $\begin{array}{l}\text { PHT secondary to COPD is thought to be of hypoxic origin and can be grouped into three categories: } \\
\text { i) vascular remodeling, } \\
\text { ii) reduction in the total number of pulmonary vessels (shown in experimental models for patients with emphysema), and } \\
\text { iii) pulmonary thrombosis } \\
\text { PAB=PCWP + (COXPVR). Changes in PCWP, CO, and PVR are responsible for PAP increase. PVR increases with hypoxia, chronic } \\
\text { inflammation, airflow limitation, hypercapnia, acidosis, and polycythemia leading vascular remodeling, vasoconstriction, hyperviscosity, } \\
\text { and fibrosis. }\end{array}$ \\
\hline Diagnosis & 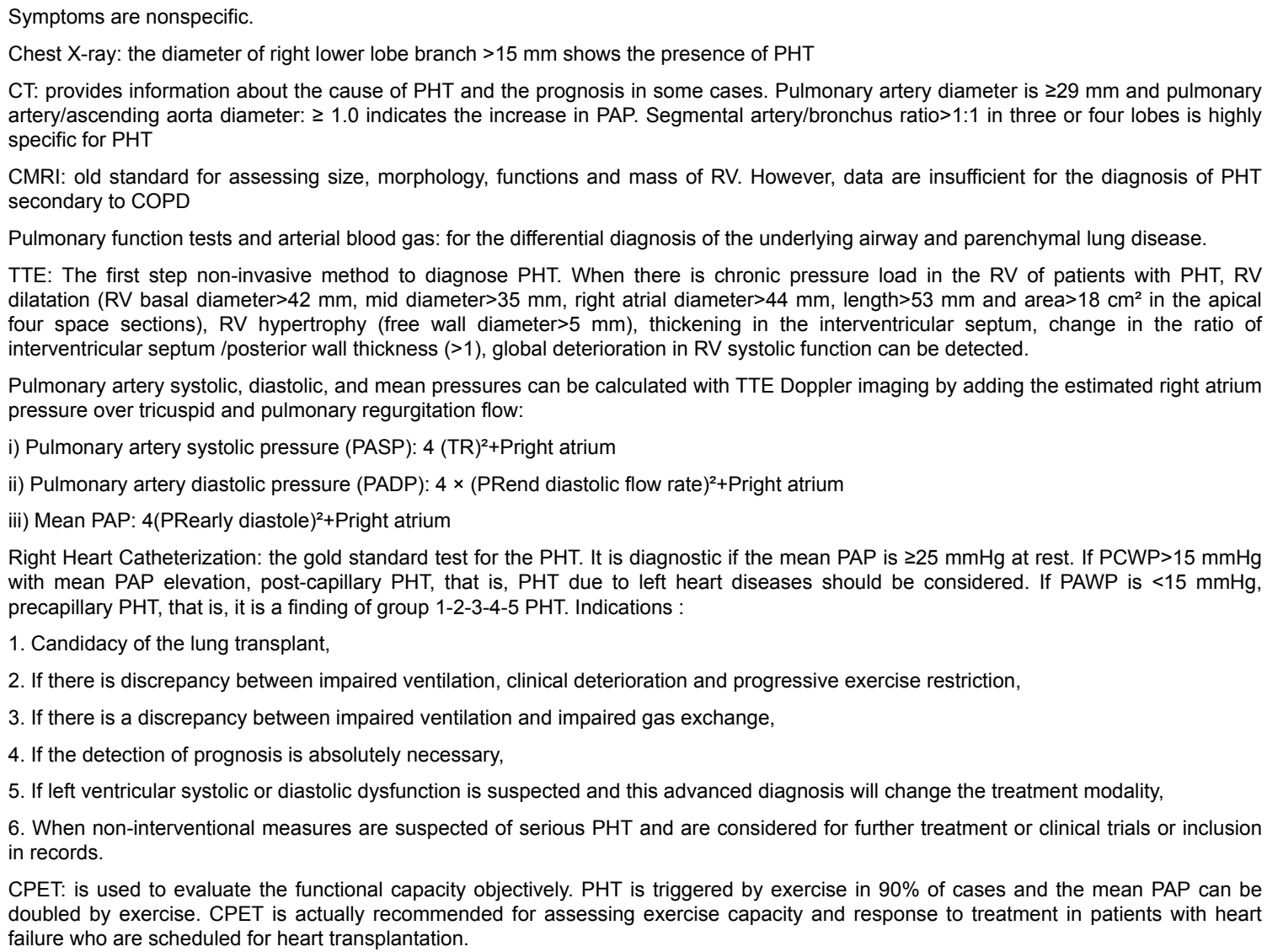 \\
\hline
\end{tabular}

Table 1: Take home messages. 
When PHT secondary to COPD is described, it is often referred to proportional or disproportional PHT. Proportional PHT is based on the assumption that the underlying parenchymal remodeling process, accompanied by hypoxia, results in an increase in pulmonary vascular resistance, leading to a "natural" loss in the area of total vascular crosssection.13 Non-proportional PHT is the presence of an unexpectedly developing PHT from pulmonary parenchymal damage.These patients have less airway obstruction, more severe hypoxia and lower carbon dioxide diffusion capacity (DLCO) [12]. The possible mechanisms are 1) progressive vascular remodeling is triggered by chronic parenchymal disease, independent of pulmonary dysfunction or 2) it can be explained as an independent, coincidental manifestation of the present lung disease [13].

In a recent publication that summarizes the results of the $5^{\text {th }}$ World PHT Symposium, it is assumed that any mean PAP above $25 \mathrm{mmHg}$ is actually considered to be non-proportional as PHT developed in cases of $>80 \%$ loss of normal lung tissue which constitutes a very small proportion of COPD patients. In addition, this terminology should be abandoned and PHT should be defined as described below for patients with COPD, idiopathic pulmonary fibrosis (IPF) or chronic pulmonary fibrosis and emphysema (CPFA), provided that the measurements are made at rest and if necessary under supportive oxygen therapy [13]:

\section{Non-PHT COPD/IPF/CPFA (mean PAP $<25 \mathrm{mmHg}$ ),}

COPD/IPF/CPFA with PHT (mean PAP $\geq 25 \mathrm{mmHg}$ ),

COPD/IPF/CPFA with severe PHT (mean PAP $\geq 35 \mathrm{~mm} \mathrm{Hg}$ or mean cardiac index with a mean PAP $\geq 25 \mathrm{mmHg}\left(<2.0 \mathrm{~L} / \mathrm{min} / \mathrm{m}^{2}\right)$.

There may also be COPD/IPF/CPFA ( $<25 \mathrm{mmHg})$ without PHT

COPD/IPF/CPFA (mean PAP $\geq 25 \mathrm{mmHg}$ ) with PHT; PHTCOPD; PHT-IPF; PHT-CPFA

PHT detected in patients with COPD can also be the pulmonary arterial hypertension (PAH) (group 1), which has been found incidentally. However, it may be difficult to distinguish between group 3 and group 1 when the respiratory function is normal or mildly impaired, and when there is no or minimal damage to the airway or lung parenchyma in the computed tomography. In these cases, patients should be directed to the experienced centers for the differential diagnosis [13].

The definition of severe PHT is based on the National Emphysema Treatment Trials (NETT), in which 1218 patients whose mean postbronchodilator the forced expiratory volume $\left(\mathrm{FEV}_{1}\right)$ value was $26.8 \%$ between 1998-2002 in the United States, and to whom volume reduction surgery was scheduled were included. In 797 patients with pulmonary artery systolic pressure (PASP) $\geq 45 \mathrm{mmHg}$ and performed right heart catheterization (if no other causes of PHT were present), severe PHT was defined as i) mean PAP $>35 \mathrm{mmHg}$, ii) mean PAP $\geq 25$ $\mathrm{mmHg}$ and limited cardiac output $\left(\mathrm{CI}<2.01 / \mathrm{min} / \mathrm{m}^{2}\right)$, or iii) pulmonary vascular resistance (PVR) $>480$ dyns $\mathrm{cm}^{-5}$ [14]. At the meeting organized in Cologne, Germany in 2010, severe PHT was defined as having at least two of the criteria above [15].

\section{Epidemiology}

The prevalence of PHT secondary to COPD varies according to the definition of PHT, the patient population studied, and the method of PHT examination (i.e., echocardiography or right heart catheterization). There was not clear information about the exact prevalence of PHT in the patient group with less severe COPD, particularly since they were not systematically evaluated by right heart catheterization due to expensive and invasive feature of this method.

In patients with moderate and severe COPD, the prevalence of PHT was reported to be $10-91 \%$, increasing parallel to the rise in COPD severity $[10,12,14,16-18]$. Hilde et al. reported the prevalence of PHT as $5 \%, 27 \%$ and $53 \%$ for COPD stage II, III and IV, respectively. On the other hand, about $17 \%$ of patients with $\mathrm{PHT}$ were reported to have COPD $[6,19]$.

Mild-to-moderate PHT was common in severe COPD cases, whereas severe PHT was rare $[13,20]$. Thabut et al. reported a mean PAP $>25 \mathrm{mmHg}$ in 50\% of COPD patients who were scheduled for lung transplantation or lung volume reduction surgery. In the same patient group, mild (mean PAP 26-35 mmHg), moderate (mean PAP 36-45 $\mathrm{mmHg}$ ), and severe (mean PAP $>45 \mathrm{mmHg}$ ) PHT prevalence were $36.7 \%, 9.8 \%$, and $3.7 \%$, respectively [17]. Importantly, the patients included in this study were in stable state of the disease and had optimal treatment of COPD.

In the NETT study published in 2002, it was reported that in a subgroup analysis of the hemodynamic characteristics of 120 patients with severe pulmonary emphysema $\left(\mathrm{FEV}_{1}=27 \%\right.$, $\left.\mathrm{DLCO}=26.7 \%\right)$; mildto-moderate PHT (mean PAP $>20 \mathrm{mmHg}$ ) was detected in $91 \%$ of patients, whereas severe PHT (mean PAP $>35 \mathrm{mmHg}$ ) was shown in only $5 \%$ of patients. 10 In the same study, right heart catheterization was performed to the patients with right ventricular systolic pressure (RVSP) $\geq 45 \mathrm{mmHg}$ based on Doppler echocardiography or to the patients whom RVSP could not be measured but clinically considered to have a high risk of PHT. In the results published in 2014; 38\% of these patients had PHT (mean PAP $\geq 25 \mathrm{mmHg}$ ), whereas severe PHT was detected in $2.2 \%$ of patients due to exclusion of patients with severe hypoxia or hypercapnia at rest and with significant PHT in Doppler echocardiography.14 The low incidence of PHT in the NETT study may be due to the exclusion of patients with severe hypoxemia and hypercapnia at rest and severe PHT detected at Doppler echocardiography.

In a retrospective study of 4930 severe COPD patients evaluated for pulmonary transplantation, it was found that mild-to-moderate PHT ( $35 \mathrm{mmHg}>$ mean PAP $\geq 25 \mathrm{mmHg}$ and PCWP $\leq 15 \mathrm{mmHg}$ ) was observed as $30.4 \%$, whereas severe PHT (mean PAP $\geq 35 \mathrm{mmHg}$ and PCWP $\leq 15 \mathrm{mmHg}$ ) was detected as $4 \%$ [21]. In another series in which 998 patients in a stable state of COPD and having optimal treatment, chronic respiratory failure and right heart catheterization were evaluated retrospectively the prevalence of severe PHT (mean $\mathrm{PAP}>40 \mathrm{mmHg}$ ) was found to be $2.7 \%$ [12]. 16 of these 27 patients had at least one other cause such as portal hypertension, collagen vascular disease, appetite suppressant drug use, left heart failure, chronic thromboembolism, obesity and obstructive sleep apnea syndrome which might lead to elevation in PAP. In recent studies, the prevalence of pulmonary embolism was reported to be $25 \%$ in unexplained COPD exacerbations [22]. Likewise, the mortality due to COPD was shown to be associated with $30 \%$ of pulmonary embolic events in the postmortem examination [23]. Based on the results of these studies; in COPD patients with PHT, a second cause that may cause PHT should routinely be investigated and treated, particularly if the mean PAP is $>35-40 \mathrm{mmHg}$ and the dyspnea level is incompatible with respiratory dysfunction. 


\section{Clinical course-prognosis}

The progression of PHT in COPD shows a slow increase as less than $1 \mathrm{mmHg}$ annually [13]. However, even modest PHT presence has an important place in clinical condition and prognosis. There is an inverse correlation between mean PAP, pulmonary vascular resistance (PVR) and mortality [13]. A $10 \mathrm{mmHg}$ increase in mean PAP at rest was together with a 4 -fold increase in mortality.19 Also, the mean PAP is a much stronger predictor than $\mathrm{FEV}_{1}$ or gas exchange variables to determine the survival. Kessler et al. [24] found that there was a significant relationship between increased exacerbation risk and PAP $>18 \mathrm{mmHg}$ in patients with moderate-severe airflow restriction; however, a significant relationship was not found between $\mathrm{FEV}_{1}, \mathrm{PaO}_{2}$ and hospitalization risk.

In 1981, when long-term oxygen therapy was not used as the usual treatment for COPD, Weitzenblum et al. [11] reported that survival at PAP $>20 \mathrm{mmHg}$ was shorter than that of normal PAP.11 According to the data of this study, the 4 -year survival rate was $72 \%$ in patients with $\mathrm{PAP}<20 \mathrm{mmHg}$ and $49 \%$ in patients with $>20 \mathrm{mmHg}$.

Conversely, 5-year survival was $36 \%$ in patients having long-term oxygen therapy with a mean $\mathrm{PAP}>25 \mathrm{mmHg}$, and $62 \%$ in patients with $\mathrm{PAP}<25 \mathrm{mmHg}$ [25].

A total of 101 COPD patients who received a new PHT diagnosis as a subgroup of the ASPIRE (Assessing the Spectrum of Pulmonary Hypertension Identified at a Referral Center) registry group ( $\mathrm{n}=1344$ patients) were followed for an average of 2.3 years [26]. In patients with severe PHT, one and three-year survival rates were reported as $70 \%$ and $33 \%$, respectively, while it were $83 \%$ and $55 \%$ in patients with mild-to-moderate PHT, respectively. The age, functional class, diffusion capacity and mixed venous oxygen saturation of the patient were identified as independent determinants of survival.

In COPD, PHT is first detected during sleep and exercise, then it progresses over time, and finally it is detected at rest. Patients with severe COPD, whether or not they have PHT at rest, may experience a two-fold increase in mean PAP value after exercise than the value at rest, and this may cause transient PHT. Therefore, PHT triggered by exercise can be detected in $90 \%$ of cases $[10,27]$. However, "exerciserelated PHT" should not be used, as there is no reliable data about the effect of prognosis on changes at which level of exercise in PAP and PVR [8].

Likewise, in patients with severe COPD, oxygen saturation may be reduced by $20-30 \%$ with decreased intercostal muscle activity in REM sleep, decreased motor neuron input, increased airway resistance, worsening ventilator/perfusion compliance, whereas the mean PAP value may increase by $20 \mathrm{mmHg}$. Although these PHT episodes in the sleep may be attributed to persistent PHT, the data in this context is contradictory [28-30]. The mean PAP in acute exacerbations of COPD may also increase by $20 \mathrm{mmHg}$ and may return to baseline levels during recovery $[28,31,32]$. Frequent attacks cause more rapid loss of lung function and worse clinical endpoints. In addition, in patients with PHT developing secondary to COPD, the risk of more serious attacks has also increased. Although the relationship between attacks and natural course of PHT in COPD is unclear, it is suggested that transient PAP increase developed from recurrent attacks may cause permanent PHT [28,31].

In patients with severe COPD, severe PHT is more frequent, as PAP increases as airway obstruction and hypoxemia get worsen. However, PHT correlates with hypoxia and DLCO, whereas it does not correlate with obstructive ventilator injury [27].

\section{Pathogenesis}

In healthy lungs, the number of elastic lamina decreases with the decrease in diameter of pulmonary artery, whereas smooth muscle increases. At first, conductive elastic arteries are present, and then they are followed by muscular arteries with diameters between 100 and 500 micrometers. Arterioles are smaller arteries less than 100 micrometers before the capillaries. They only contain a thin intima and a single layer of elastic lamina, while they normally do not contain the muscular layer.

PHT secondary to COPD is thought to be of hypoxic origin. However, more complex pathobiologic mechanisms have been introduced in recent autopsy reports of patients with severe COPD or in the study evaluating lungs removed during transplantation. Accordingly, the PHT mechanism can be grouped into three categories: vascular remodeling, reduction in the total number of pulmonary vessels (shown in experimental models for patients with emphysema), and pulmonary thrombosis [31]. Among these mechanisms, the best researched one for PHT development in patients with COPD is remodeling of the vascular bed. Pathological examination also reveals traces of hypoxia, mechanical stress, and inflammatory reaction [33].

Pulmonary vascular remodeling: The characteristic pathological finding of vascular remodeling is the smooth muscle tissue extending to the pulmonary arterioles, even pre-post-capillary vascular bed and pulmonary veins [34,35]. This condition, called muscling, causes hypertrophy, proliferation or phenotype change of contractile cells which are precursors of smooth muscle cells and identified as pericytes, or the exchange of intermediate cells [31]. Another finding is intimal thickening with loss of endothelial cell function and decreased luminal diameter resulting from proliferation of smooth muscle cells and accumulation of elastin-collagen tissue with loss of contractile function in the pulmonary arteries and arterioles [28]. In patients with PHT secondary to COPD, inflammation also occurs, particularly due to $\mathrm{CD} 8+\mathrm{T}$ cells [36].

Unlike patients with PAH, there is damage in the alveolus and its associated vasculature due to underlying lung disease in patients with PHT secondary to COPD. This damage increases the PVR by reducing the pulmonary vascular area [37]. Another important pathological difference is the absence of plexiform and angiomatoid lesions due to unorganized endothelial proliferation in PAH [38].

Remodeling of pulmonary arteries is not only seen in advanced COPD patients, but also in non-hypoxic mild COPD patients $[28,36,39,40]$. However, "muscling" in pulmonary arterioles may be frequently observed in COPD patients who have not yet developed PHT but undergone organ transplantation [41]. These findings suggest that the degree of reshaping of the pulmonary arteries is not proportional to the severity of PHT and COPD, and other factors may play a role in the clinical manifestation of PHT, although changes in the pulmonary vascular structure may be preliminary.

Endothelial dysfunction: Endothelial dysfunction was demonstrated in all COPD stages. Endothelial dysfunction is due to the equilibrium disturbance between vasculatory functions and vasoactive mediators regulating cell growth at the same time. While potent vasodilator and antiproliferative endothelial-mediated nitric oxide (NO) and prostacyclin (PGI2) synthesis are reduced, endothelin-1 (ET-1), a potent vasoconstructor and mitogenic effect of arterial smooth muscle cells, is increased [28]. This leads to the onset of pulmonary vasoconstriction and vascular remodeling. Vascular remodeling also 
increases endothelial dysfunction. In addition, cytokines and growth factors such as vascular endothelial growth factor (VEGF), atrial (ANP) and brain natriuretic peptide (BNP), serotonin, vasoactive intestinal peptide and adrenomedullin may also contribute to endothelial dysfunction in this group of patients [20].

Inflammation: The potential role of inflammation in the pathogenesis of PHT secondary to COPD remains unclear, and inflammatory cells are held responsible for structural and functional changes in the vascular wall [42]. Peinado et al. [39] reported that there was an infiltration of the adventitia layer of pulmonary artery by inflammatory cells and they showed that there was a relationship with the number of inflammation cells, the expansion in the intimal layer and endothelial cell dysfunction. It was reported by Chaout et al. [43] that circulating IL-6 levels were associated with the mean PAP. It was also suggested that systemic inflammation markers, C-reactive protein (CRP), tumor necrosis factor alpha (TNF- $\alpha$ ), monocyte chemoattractant protein-1 (MCAP-1), soluble intercellular adhesion molecule-1 (sICAM-1), platelet-derived growth factor (PDGF) were correlated with PHT secondary to COPD [20].

Smoking: It is known that smoking is a risk factor for vascular disease in both coronary and systemic arteries in both active and passive smoking, and it disrupts endothelial functions. Smokers with normal pulmonary function have also been shown that smoking causes structural changes in pulmonary muscular arteries, suggesting that it may have a direct effect on vasculature [28]. Exposure of pulmonary endothelial cells to cigarette smoke causes an irreversible inhibition of endothelial nitric oxide synthase (eNOS) activity. Also, smooth muscle cell proliferation of pulmonary artery, increase in vascular endothelial growth factor expression, inflammatory cell infiltration $(\mathrm{CD}+8 \mathrm{~T}$ cell infiltration) and finally endothelial dysfunction were also identified in smokers. Likewise, it was shown in animal experiments that there was pre-capillary vessels muscularisation as a result of chronic exposure to the smoking [28]. In the light of these evidences, it can be concluded that there is decrease in eNOS expression induced by toxic products of smoking at the beginning of COPD, while pulmonary vascular remodeling is induced in chronic hypoxia in which there is endothelial dysfunction.

\section{Pathophysiology}

PAP is the result of PCWP and the driving pressure on the pulmonary circulation. On the other hand, the driving pressure in the pulmonary circulation equals to the product of cardiac output $(\mathrm{CO})$ and PVR: $\mathrm{PAB}=\mathrm{PCWP}+(\mathrm{CO} \times \mathrm{PVR})$. In this circumstance, changes in PCWP, CO, and PVR are responsible for PAP increase.

Many structural and functional factors that affect different locations on the pulmonary vascular system are responsible for the development of PHT in COPD [20]. These are the main factors leading to and chronic inflammation, vasoconstriction, vascular remodeling and consequently PHT $[20,28,44]$. Apart from this, PVR also increases with restriction of airflow, hypercapnia, acidosis, polycythemia and inflammation.

\section{Hypoxia}

Alveolar hypoxia is one of the most important causes of PVR increase.

Acute alveolar hypoxia: It causes hypoxic pulmonary vasoconstriction (HPV) in the smooth muscles of small pulmonary arteries $(<500 \mu \mathrm{m})$ leading to increased PVR and PAP. HPV begins and disappears rapidly within seconds due to contractions of smooth muscles in the small pulmonary artery. This mechanism is preliminary in acute exacerbations of COPD, exertion and sleep-related PHT attacks [31]. In fact, HPV is a defensive mechanism that reduces perfusion in poorly ventilated or non-ventilated lung units, redirects blood to better aerated units, restores ventilation-perfusion balance, and maintains blood oxygen levels [45]. According to pulmonary circulation response to acute hypoxia, patients can be assessed as those having response to acute hypoxia (significant increase in PVR and PAP), those with poor response or those without response [46].

Our knowledge of the effects of chronic hypoxia on pulmonary circulation is often derived from animal models and in-vitro experiments. Accordingly, chronic hypoxia, causing vascular remodeling, leads to PHT $[20,47]$. In chronic hypoxia, the synthesis and release of ET-1 increases, while NO and PGI2 decrease. As a result, pulmonary artery tone increases. Chronic hypoxia also induces angiogenesis via systemic inflammatory response and VEGF [48]. Increased interleukin 6 (IL-6) during hypoxia contributes to remodeling by triggering the reduction of cell proliferation and apoptosis in vascular endothelium, smooth muscle cells and fibroblasts [48]. In addition, chronic hypoxia can lead to rise in PVR by causing increased blood viscosity secondary to the polycythemia [49]. Polycythemia may also enhance HPV due to the removal of too much NO from the pulmonary circulation [50].

Although hypoxia has an important contribution to the development of PHT secondary to COPD, it is not the only factor in the emergence of PHT [20]. Findings supporting this circumstance can be listed as follows: 1) non-normalization of PAP with oxygen therapy [51] and variability of the hemodynamic response to oxygen therapy $[52], 2)$ the relationship between PAP and oxygen partial pressure $\left(\mathrm{PaO}_{2}\right)$ is not strong and cannot always be shown [3,10]) changes in pulmonary vasculature and detection of endothelial dysfunction in non-hypoxic mild COPDs $[39,53,54]$ and 4) observation of PAP increase in animal models exposed to cigarette smoke before COPD [55]. As a result, hypoxia plays a key role in the development of PHT in this patient group, but it cannot be held responsible alone for all hemodynamic changes.

\section{Right Ventricular Functions}

The right ventricle (RV) acts as an volume pump and has difficulty to adapt with acute increases in pressure as it has a thinner wall structure, larger volume-surface area than the left ventricle (LV), and the PAP is normally low and the compliance of pulmonary artery is high [56]. The RV ejection fraction (EF) is determined by the preload, afterload, RV contraction.

Since PAP is usually not very high and the rate of progression of PHT is slow in patients with COPD, RV has enough time to adapt to moderate pressure increase. The slow increase in PAP leads to RV hypertrophy over time. In addition, RV becomes dilated, end diastolic and systolic volume increase, and the EF decreases while the pulse volume is maintained $[28,31]$. The best way to determine RV functions is to determine the relationship between end-systolic pressure and volume. Studies conducted by this method showed that RV contractility was reduced at acute exacerbations (in the case of acidosis and infection) accompanied by significant peripheral edema, whereas it was within normal range independent of PAP in clinically stable COPD patients $[28,31]$. 
In addition to the modifications above, RV dilatation may cause the interventricular septum to be pushed towards the LV, reducing the left ventricular filling and cardiac output [57]. On the other hand, increased RVSP may contribute to the preservation of LV EF by helping to release LV and pushing LV through free wall through the septum [58].

Vizza et al. [59] reported that the prevalence of RV dysfunction was detected as $59 \%$ in 158 COPD patients who were underwent lung transplantation, whereas it was $61 \%$ in patients with a1-AT emphysema. Likewise, the mean RV EF in 120 patients with severe emphysema was $34 \pm 8 \%$, and $\mathrm{PAP}$ and $\mathrm{PaO}_{2}$ have been reported to be predictors of RV EF [10].

\section{Peripheral edema}

In patients with COPD, peripheral edema is the result of a balance between the mechanisms that form the edema and protect it from edema. Peripheral edema can develop or worsen during acute attacks.

The renal angiotensin aldosterone system (RAAS) stimulated by reduced renal plasma flow due to the sympathetic system activation and hypoxia, hypercapnia-induced sympathetic system exacerbate venous congestion, previously stimulated by right atrial distension and increases the tubular absorption of sodium and water. In hypoxic and hypercapnic patients, hyponatremia and vasopressin release also contribute to the edema formation. In contrast, ANP is released from the dilated right atrium wall and plays an anti-edema role with diuretic, natriuretic and vasodilator effect, but often cannot resist the mechanisms that cause edema [60].

\section{Exercise}

In patients with COPD, PHT can be detected by exercise, even if there is no PHT at baseline. Kessler et al. [61] showed that in 7-year follow-up of patients who did not basically have PHT but detected PHT during exercise, the risk of developing PHT was higher. Two other important results of this study were that the rate of progression of PHT was slow $(0.4 \mathrm{mmHg} /$ year $)$ and correlated with arterial oxygen pressure. Hilde et al. [19] reported that the absolute increase in mean PAP secondary to the increase in cardiac workload and cardiac output as response to maximal exercise by right heart catheterization in stable COPD patients was not significant between the PHT group and the non-PHT group, but there was a significant increase compared to the baseline values.

Several mechanisms for exercise-induced PHT have been proposed such as hypoxic vasoconstriction, decreased capillary bed due to emphysema, and impaired endothelium-mediated relaxation factors [28]. In healthy individuals, decrease in PVR by exercise are not observed secondary to possible pulmonary vasoconstriction in patients with advanced COPD. The causes of pulmonary vasoconstriction include hypoxic pulmonary vasoconstriction, increased sympathetic activation, and decreased $\mathrm{pH}$. In addition, alveolar pressure increases with dynamic hyperinflammation due to reduction of expiratory flow during exercise. Likewise, there are significant fluctuations in intrathoracic pressure in the presence of airway obstruction during exercise. These changes in intrathoracic pressure cause lowered cardiac output due to decreased systemic venous return or increase in afterload [28].

Therefore, in advanced COPD patients with mild PHT (25-30 $\mathrm{mmHg})$ at rest, there is a significant increase in PAP $(50-60 \mathrm{mmHg})$ with an increase in cardiac output after constant moderate level exercise. When clinically assessed, an exercise at this level can coincide with daily activities, and therefore, significant PHT can develop in daily activities [31].

\section{Clinical Symptoms - Diagnostic Methods}

\section{Symptoms and clinical findings}

Symptoms of PHT in patients with COPD are nonspecific and it is difficult to distinguish them from the symptoms of COPD. Therefore, it is difficult to clinically establish the diagnosis of PHT secondary to COPD. The main symptom is mostly exertional dyspnea and decreased exercise capacity. Cough, sputum due to COPD and cigarette smoking are common in patient's history. The first finding that raises suspicion is the presence of peripheral edema, mostly due to RV dysfunction. Apart from that, hemoptysis secondary to the bronchial artery rupture, vocalization due to left laryngeal nerve pressure secondary to the pulmonary artery dilatation, wheezing, chest pain/myocardial ischemia due to the occlusion of left main coronary artery are other complaints [8].

On physical examination, left parasternal pulsation secondary to the PHT can be detected during palpation. The heart sounds cannot be assessed due to the hyperinflated lungs in most cases, but the split second sound, loud P2, left parasternal systolic murmur due to tricuspid insufficiency, diastolic murmur due to pulmonary insufficiency can be heard. Likewise, in severe PHT, jugular venous congestion, hepatomegaly, peripheral edema and acid may be detected.

\section{Radiology}

The degree of PHT and radiological findings are not correlated and normal radiological findings do not exclude the presence of PHT. Radiological findings in patients with $\mathrm{PAH}$ are dilatation in central pulmonary vessels, right atrium and ventricular dilatation in advanced disease.

On chest X-ray, the diameter of right lower lobe branch $>15 \mathrm{~mm}$ shows the presence of PHT [15]. Likewise, chest films are helpful for differential diagnosis of group 2 PHT, group 3 PHT and arterial/ venous PHT (increased or decreased artery:vein ratio) [8] In patients with severe COPD, the RV shadow acquires a lobular appearance, the cardiothoracic ratio becomes greater than 0.5 , and the disease may cause retrosternal loss of airspace on lateral radiographs [60].

Computed tomographic examination is a widely used technique for identifying vascular, cardiac, parenchymal, and mediastinal pathologies. The diagnosis of PHT (RV and right atrium dilatation) provides information about the cause of PHT and the prognosis in some cases. Pulmonary artery diameter is $\geq 29 \mathrm{~mm}$ and pulmonary artery/ascending aorta diameter: $\geq 1.0$ indicates the increase in PAP. Segmental artery/bronchus ratio $>1: 1$ in three or four lobes is highly specific for PHT [8].

Cardiac magnetic resonance imaging is the gold standard for assessing size, morphology, functions and mass of RV. However, data are insufficient for the diagnosis of PHT secondary to COPD. MRI also provides basal and follow-up prognostic information in patients with PHT [8]. 


\section{Pulmonary Function Tests and Arterial Blood Gas}

Pulmonary function tests and arterial blood gas sampling are necessary for the differential diagnosis of the underlying airway and parenchymal lung disease. In arterial blood gas of patients with COPD, $\mathrm{PaO}_{2}$ is decreased, $\mathrm{PaCO}_{2}$ is normal/increased. HPV begins when $\mathrm{PaO}_{2}$ is $<55-60 \mathrm{mmHg}$. Chronic hypercapnia enhances the risk of developing PHT due to acidosis [60]. As airway obstruction increases, peripheral airways in expiration are more easily collapsed by increased airway resistance which leads to an increase in intraalveolar pressure, causing PHT. Yetkin et al. [62] showed that there was a significant negative correlation between the decrease in $\mathrm{FEV}_{1}$ and the mean PAP.

\section{Electrocardiography (ECG)}

ECG is specific (>85\%) but less sensitive (40\%) for PHT. RV hypertrophy is diagnostic with the percentage of $25-40 \%$ and is not parallel to the severity of underlying PHT. Supraventricular arrhythmias, particularly atrial flutter, atrial fibrillation, are common rhythm disorders in advanced disease. Ventricular arrhythmias are rare.

In ECG: i) P-pulmonary due to right atrial dilatation in DII, DIII and aVF, ii) findings of RV hypertrophy: +120 degree QRS axis, predominant $\mathrm{R}$ wave in $\mathrm{V} 1$ and $\mathrm{R} / \mathrm{S}<1$ in $\mathrm{V} 5-6$, iii) incompletecomplete right bundle branch block, iv) depolarization anomalies in precordial leads and inferior leads, v) advanced QRS enlargement and prolonged QTc may be seen.

\section{Transthoracic Echocardiography (TTE)}

TTE is the first step non-invasive method to diagnose PHT. It provides direct and indirect findings about the elevation of the pulmonary artery pressure and its cause. However, these findings may not be seen in the early stage of the disease. In addition, adequate echocardiographic images may not always be obtained due to the hyperinflated lungs and right rotation of the heart. The positive predictive value is $68 \%$ and the negative predictive value is $67 \%$ when compared with the values in right heart catheterization [7].

When there is chronic pressure load in the RV of patients with PHT, $\mathrm{RV}$ dilatation ( $\mathrm{RV}$ basal diameter $>42 \mathrm{~mm}$, mid diameter $>35 \mathrm{~mm}$, right atrial diameter $>44 \mathrm{~mm}$, length $>53 \mathrm{~mm}$ and area $>18 \mathrm{~cm}^{2}$ in the apical four space sections), RV hypertrophy (free wall diameter $>5 \mathrm{~mm}$ ), thickening in the interventricular septum, change in the ratio of interventricular septum/posterior wall thickness (>1), global deterioration in RV systolic function can be detected. Likewise, chronic pressure load in the RV causes changes in the shape and movements of the interventricular septum. LV is oval in a normal heart and it maintains its shape throughout the entire cycle. On the other hand, when the RV pressure increases, the normal interventricular septum curve becomes flattened and D-shape is observed in the LV. A further increase in pressure results in the displacement of the interventricular septum to LV more. This displacement in the interventricular septum is preserved during the entire heart cycle (systole and diastole) differently from the RV volume load (only in the diastole). Flattening in interventricular septum movements are also observed [63]. While evaluating RV wall movements, examination should be done from multiple windows. In addition, RV systolic function can be evaluated quantitatively. The most commonly used parameters for this purpose are: tissue Doppler tricuspid lateral anulus systolic velocity: S'; tricuspid valve annular plane systolic displacement: TAPSE; RV fractional area change: RV-FAD. S' velocity $<10 \mathrm{~cm} / \mathrm{sec}$,
RV-FAD $<35 \%$ and TAPSE $<16 \mathrm{~mm}$ indicates $\mathrm{RV}$ systolic dysfunction [63].

Pulmonary artery systolic, diastolic, and mean pressures can be calculated with TTE Doppler imaging by adding the estimated right atrium pressure over tricuspid and pulmonary regurgitation flow. However, adequate examination of the tricuspid regurgitation (TR) flow in patients with COPD is limited due to hyperinflated lung tissue (24-77\%). The right atrium pressure is estimated to be between 5 and $20 \mathrm{mmHg}$, which is identified by the presence of inferior vena cava width and inspiratory contraction $[31,64]$.

Pulmonary artery systolic pressure (PASP): In cases with absence of significant right ventricular outflow tract and pulmonary valve obstruction, it is calculated by adding RVSP to the right atrium pressure. In this way, the Bernoulli equation is used to measure RVSP over TR flow. $\mathrm{RVSP}=4(\mathrm{TR})^{2}$ and $\mathrm{PASP}=\mathrm{RVSP}+\mathrm{Pright}$ atrium are calculated by measuring the maximum TR flow $(\mathrm{m} / \mathrm{s})$.

Pulmonary artery diastolic pressure (PADP): It is also calculated on the basis of pulmonary regurgitation (PR) flow. This time, however, the diastole end flow velocity of the PR flow takes place in the Bernoulli equation. Under normal conditions, the diastolic pressure of pulmonary artery equals or is slightly elevated to the RV diastolic pressure. Therefore, the rate of regurgitation flow is very low. However, as the PHT and PADP increase, more pressure gradient occurs and the insufficiency flow increases. Therefore, if the end-diastolic flow velocity of PR is above $2 \mathrm{~m} / \mathrm{s}$, it means that there is significant PHT. PADP: It is calculated as $4 \times(\text { PRend diastolic flow rate })^{2}+$ Pright atrium.

Mean PAP: The early diastolic peak flow velocity of the PR flow is also measured by using the Bernoulli equation. Mean $P A P=4$ (PRearly diastole $)^{2}+$ Pright atrium

According to the guidelines of the European Society of Cardiology for diagnosis and treatment of PHT, conditions that suggest the existence of PHT in terms of TR flow and PASP (when the right atrium pressure is predicted as $5 \mathrm{mmHg}$ ) are: [9]

TR $\leq 2.8 \mathrm{~m} / \mathrm{sec}$ and PASP $\leq 36 \mathrm{mmHg}$, no additional echocardiographic findings: PHT is not possible

TR $\leq 2.8 \mathrm{~m} / \mathrm{sec}$ and PASP $\leq 36 \mathrm{mmHg}$, additional echocardiographic findings: PHT is possible

TR 2.9-3.5 m/sec and PASP 37-50 mmHg, with or without additional echocardiographic findings: $\mathrm{PHT}$ is possible

TR $>3.5 \mathrm{mmHg}$ and PASP $>50 \mathrm{mmHg}$, with or without additional echocardiographic findings: PHT is possible.

\section{Right heart catheterization}

Right heart catheterization is the gold standard test for the PHT. However, it is not applied to every patient, since it is an invasive examination. Central venous pressure, right atrium, RV, PAP and PCWP are measured by right heart catheterization. Possible left-right shunt is excluded by performing an oxygen study. In addition, vasoreactivity testing (VRT) should be performed in patients who are diagnosed with idiopathic PHT, hereditary PHT and anorexiant drug use-induced PHT before planning medical treatment and in patients with congenital heart disease in the evaluation of mortality/morbidity after surgery. The application of VRT is not recommended, since the level of evidence is lower in other PHT subgroups [9]. 
It is diagnostic if the mean PAP is $\geq 25 \mathrm{mmHg}$ at rest. If $\mathrm{PAWP}>15$ mmHg with mean PAP elevation, post-capillary PHT, that is, PHT due to left heart diseases should be considered. If PAWP is $<15 \mathrm{mmHg}$, precapillary PHT, that is, it is a finding of group 1-2-3-4-5 PHT.

Indications for right heart catheterization in patients with chronic pulmonary disease can be listed as: [9]

Candidacy of the lung transplant,

If there is discrepancy between impaired ventilation, clinical deterioration and progressive exercise restriction,

If there is a discrepancy between impaired ventilation and impaired gas exchange,

If the detection of prognosis is absolutely necessary,

If left ventricular systolic or diastolic dysfunction is suspected and this advanced diagnosis will change the treatment modality,

When non-interventional measures are suspected of serious PHT and are considered for further treatment or clinical trials or inclusion in records.

\section{Laboratory}

There is no biochemical marker for screening of PHT secondary to COPD. BNP is released due to increase in tension at the wall of the atrium and ventricle. Recent studies have shown that BNP and its precursor NT-proBNP are elevated in the presence of acute exacerbations of COPD (increased PHT) and presence of severe PHT. However, the specificity of BNP and NT-pro-BNP is also low, since it may also arise in left heart disease [65]. Likewise, normal BNP/NTpro-BNP values do not exclude the presence of PHT. Therefore, more and larger studies are needed to determine the location of BNP and NT-pro-BNP for the diagnosis of PHT in COPD.

Polycythemia is developed by chronic hypoxia in the presence of COPD and the increase in viscosity begins. This leads to resistance to blood flow in the lungs, increased preload and right heart work, leading to the development of RV insufficiency and cor pulmonale.

\section{Exercise tests}

A cardiopulmonary exercise test (CPET) is used to evaluate the functional capacity objectively accompanied by a doctor. If it is recalled that PHT is triggered by exercise in $90 \%$ of cases and the mean PAP can be doubled by exercise whether there is PHT at rest, PHT should be considered, particularly in those with low exercise capacity not associated with symptoms [10,27].

CPET is actually recommended for assessing exercise capacity and response to treatment in patients with heart failure who are scheduled for heart transplantation. Bicycle ergometer or treadmill can be used for stress testing. $\mathrm{VO}_{2}$ and $\mathrm{VCO}_{2}$, heart rate, blood pressure are measured during the test. ECG and oxygen saturation are followed. The test is terminated if chest pain suggesting chest pain, ischemic ECG changes, second-third degree heart block, $20 \mathrm{mmHg}$ and more drop in systolic blood pressure, falling of oxygen saturation below $80 \%$ in the presence of ischemia and its symptoms, sudden development of pallor, loss of coordination, dizziness and weakness, shortness of breath and mental confusion develop [27].

The 6-minute walk test is a reproducible, lower cost form of CPET developed by Balke for the first time in 1963. The standard protocol is followed by a 30 -meter uninterrupted corridor where every three meters are marked after a quick and appropriate emergency intervention is possible. For the test, the patient is informed about wearing comfortable clothes and shoes. In addition, verbal encouragement is performed during the test. The test is terminated if the patient has chest pain, intolerable dyspnea, leg cramps, nausea, pale appearance, drowsiness, or development of condition before faintness. The test is repeated three times and the longest walking distance is taken into account, provided that one hour resting period is left. Before and after the test, heart rate, blood pressure, dyspnea level and oxy hemoglobin level according to Borg scale are recorded.

\section{Other tests}

Ventilation perfusion scintigraphy and spiral computed tomography are necessary to exclude thromboembolic events in COPD patients with severe PHT. Sleep tests should also be performed, as sleep apnea can also lead to severe PHT in COPD patients [12]. Isotopic right ventriculography is an examination used in the assessment of right ventricular global functions, but not the diagnosis of PHT.

\section{Conclusion}

In conclusion, PHT is frequently observed in COPD and complaints usually progress increasingly, whereas functional capacity gradually decreases. Although pathogenesis is complex, it often involves HPV and pulmonary vascular remodeling. A detailed diagnostic evaluation is needed to detect etiology of other secondary edema such as sleep apnea and heart failure. Patients with severe PHT or severe RV failure findings, where alternative diagnoses (e.g. PAH) are considered or $\mathrm{PAH}$-specific therapy/pulmonary transplantation is indicated, are recommended to be transferred to specialized centers in this area as soon as possible.

\section{References}

1. Grubu TTDKÇ (2014) Chronic obstructive pulmonary disease (COPD) protection, diagnosis and treatment report. Turk Thorac J 15: S1-S11.

2. Buist AS, McBurnie MA, Vollmer WM, Gillespie S, Burney P, et al. (2007) International variation in the prevalence of COPD (the BOLD Study): a population-based prevalence study. Lancet 370: 741-750.

3. Kocabas A, Hancioglu A, Turkyilmaz S (2006) Prevalence of COPD in Adana, Turkey (BOLD-Turkey Study) American Thoracic Society A543.

4. GOLD, GIfCOLD (2017) Global strategy for the diagnosis, management and prevention of chronic obstructive pulmonary disease.

5. Mathers CD, Loncar D (2006) Projections of global mortality and burden of disease from 2002 to 2030. PLoS Med 3: e442.

6. Smith MC, Wrobel JP (2014) Epidemiology and clinical impact of major comorbidities in patients with COPD. Int J Chron Obstruct Pulmon Dis 9: 871-888.

7. Simonneau G, Gatzoulis MA, Adatia I, Celermajer D, Denton C (2013) Updated clinical classification of pulmonary hypertension. J Am Coll Cardiol 62: D34-D41.

8. Galiè N, Humbert M, Vachiery JL (2016) 2015 ESC/ERS Guidelines for the diagnosis and treatment of pulmonary hypertension: The Joint Task Force for the Diagnosis and Treatment of Pulmonary Hypertension of the European Society of Cardiology (ESC) and the European Respiratory Society (ERS): Endorsed by: Association for European Paediatric and Congenital Cardiology (AEPC), International Society for Heart and Lung Transplantation (ISHLT). Eur Heart J 37: 67-119.

9. Galiè N, Hoeper MM, Humbert (2009) Guidelines for the diagnosis and the treatment of pulmonary hypertension: The Task Force for the diagnosis and treatment of pulmonary hypertension of the European Society of Cardiology (ESC), and the European Respiratory Society 
(ERS), endorsed by the International Society of Heart and Lung Transplantation (ISHLT). Eur Heart J 30: 2493-2537.

10. Scharf SM, Iqbal M, Keller C, Criner G, Lee S, et al. (2002) Hemodynamic characterization of patients with severe emphysema. Am J Respir Crit Care Med 166: 314-322.

11. Weitzenblum E, Hirth C, Ducolone A, Mirhom R, Rasaholinjanahary J, et al. (1981) Prognostic value of pulmonary artery pressure in chronic obstructive pulmonary disease. Thorax 36: 752-758.

12. Chaouat A, Bugnet AS, Kadaoui N, Schott R, Enache I, et al. (2005) Severe pulmonary hypertension and chronic obstructive pulmonary disease. Am J Respir Crit Care Med 172: 189-194.

13. Seeger W, Adir Y, Barbera JA (2013) Pulmonary hypertension in chronic lung diseases. J Am Coll Cardiol 62: D109-D116.

14. Minai OA, Fessler H, Stoller JK, Criner GJ, Scharf SM, et al. (2014) Clinical characteristics and prediction of pulmonary hypertension in severe emphysema. Respir Med 108: 482-490.

15. Hoeper MM, Andreas S, Bastian A, Claussen M, Ghofrani HA, et al. (2011) Pulmonary hypertension due to chronic lung disease: updated Recommendations of the Cologne Consensus Conference 2011. Int Cardiol 1: S45-53.

16. Divo M, Cote C, de Torres JP, Casanova C, Marin JM, et al. (2012) Comorbidities and risk of mortality in patients with chronic obstructive pulmonary disease. Am J Respir Crit Care Med 186: 155-161.

17. Thabut G, Dauriat G, Stern JB, Logeart D, Lévy A, et al. (2005) Pulmonary hemodynamics in advanced COPD candidates for lung volume reduction surgery or lung transplantation. Chest 127: 1531-1536.

18. Doi M, Nakano K, Hiramoto T, Kohno N (2003) Significance of pulmonary artery pressure in emphysema patients with mild-tomoderate hypoxemia. Respir Med 97: 915-920.

19. Hilde JM, Skjørten I, Hansteen V, Melsom MN, Hisdal J, et al. (2013) Haemodynamic responses to exercise in patients with COPD. Eur Respir J 41: 1031-1041.

20. Wrobel JP, Thompson BR, Williams TJ (2012) Mechanisms of pulmonary hypertension in chronic obstructive pulmonary disease: A pathophysiologic review. J Heart Lung Transplant 31: 557-564.

21. Cuttica MJ, Kalhan R, Shlobin OA, Ahmad S, Gladwin M, et al. (2010) Categorization and impact of pulmonary hypertension in patients with advanced COPD. Respir Med 104: 1877-1882.

22. Tillie-Leblond I, Marquette $\mathrm{CH}$, Perez T, Scherpereel A, Zanetti C, et al. (2006) Pulmonary embolism in patients with unexplained exacerbation of chronic obstructive pulmonary disease: Prevalence and risk factors. Ann Intern Med 144: 390-396.

23. Ambrosetti M, Ageno W, Spanevello A, Salerno M, Pedretti RF (2003) Prevalence and prevention of venous thromboembolism in patients with acute exacerbations of COPD. Thromb Res 112: 203-207.

24. Kessler R, Faller M, Fourgaut G, Mennecier B, Weitzenblum E (1999) Predictive factors of hospitalization for acute exacerbation in a series of 64 patients with chronic obstructive pulmonary disease. Am J Respir Crit Care Med 159: 158-164.

25. Oswald-Mammosser M, Weitzenblum E, Quoix E, Moser G, Chaouat A (1995) Prognostic factors in COPD patients receiving long-term oxygen therapy. Importance of pulmonary artery pressure. Chest 107: 1193-1198.

26. Hurdman J, Condliffe R, Elliot CA, Swift A, Rajaram S, et al. (2013) Pulmonary hypertension in COPD: Results from the ASPIRE registry. Eur Respir J 41: 1292-1301.

27. Preston I (2009) Pulmonary Hypertension in chronic obstructive pulmonary disease: Diagnosis and management. Advances in $\mathrm{PH}$ : Pulmonary Hypertension Association 8.

28. Barberà JA, Peinado VI, Santos S (2003) Pulmonary hypertension in chronic obstructive pulmonary disease. Eur Respir J 21: 892-905.

29. Fletcher EC, Luckett RA, Miller T, Costarangos C, Kutka N, et al. (1989) Pulmonary vascular hemodynamics in chronic lung disease patients with and without oxyhemoglobin desaturation during sleep. Chest 95: 757-764.
30. Chaouat A, Weitzenblum E, Kessler R, Schott R, Charpentier C, et al. (2001) Outcome of COPD patients with mild daytime hypoxaemia with or without sleep-related oxygen desaturation. Eur Respir J 17: 848-855.

31. Chaouat A, Naeije R, Weitzenblum E (2008) Pulmonary hypertension in COPD. Eur Respir J 32: 1371-1385.

32. Shujaat A, Bajwa AA, Cury JD (2012) Pulmonary Hypertension Secondary to COPD. Pulm Med 2012.

33. Naeije R, Barberà JA (2001) Pulmonary hypertension associated with COPD. Crit Care 5: 286-289.

34. Rabinovitch M, Gamble W, Nadas AS Miettinen OS, Reid L (1979) Rat pulmonary circulation after chronic hypoxia: Hemodynamic and structural features. Am J Physiol 236: H818-82.

35. Hoffmann J, Wilhelm J, Marsh LM, Ghanim B, Klepetko W, et al. (2014) Distinct differences in gene expression patterns in pulmonary arteries of patients with chronic obstructive pulmonary disease and idiopathic pulmonary fibrosis with pulmonary hypertension. Am J Respir Crit Care Med 190: 98-111.

36. Peinado VI, Barbera JA, Abate P, Ramírez J, Roca J, et al. (1999) Inflammatory reaction in pulmonary muscular arteries of patients with mild chronic obstructive pulmonary disease. Am J Respir Crit Care Med 159: 1605-1611.

37. Bignon J, Khoury F, Even P, Andre J, Brouet G (1969) Morphometric study in chronic obstructive bronchopulmonary disease. Pathologic, clinical, and physiologic correlations. Am Rev Respir Dis 99: 669-695.

38. Pietra GG, Capron F, Stewart S, Leone O, Humbert M, et al. (2004) Pathologic assessment of vasculopathies in pulmonary hypertension. J Am Coll Cardiol 43: 25S-32S.

39. Dournes G, Laurent F, Coste F, Dromer C, Blanchard E, et al. (2015) Computed tomographic measurement of airway remodeling and emphysema in advanced chronic obstructive pulmonary disease. Correlation with pulmonary hypertension. Am J Respir Crit Care Med 191: 63-70.

40. Santos S, Peinado VI, Ramírez J, Melgosa T, Roca J, et al. (2002) Characterization of pulmonary vascular remodelling in smokers and patients with mild COPD. Eur Respir J 19: 632-638.

41. Carlsen J, Hasseriis Andersen K, Boesgaard S, Iversen M, et al. (2013) Pulmonary arterial lesions in explanted lungs after transplantation correlate with severity of pulmonary hypertension in chronic obstructive pulmonary disease. J Heart Lung Transplant 32: 347-354.

42. Voelkel NF, Tuder RM (1995) Cellular and molecular mechanisms in the pathogenesis of severe pulmonary hypertension. Eur Respir J 8: 2129-2138.

43. Chaouat A, Savale L, Chouaid C, Tu L, Sztrymf B, et al. (2009) Role for interleukin-6 in COPD-related pulmonary hypertension. Chest 136: 678-687.

44. Chaouat A (2009) Chronic cor pulmonale in COPD. Rev Mal Respir 26: 1184-1185.

45. Hales CA (1985) The site and mechanism of oxygen sensing for the pulmonary vessels. Chest 88 : 235S-240S.

46. Weitzenblum E, Schrijen F, Mohan-Kumar T, Colas des Francs V, Lockhart A (1988) Variability of the pulmonary vascular response to acute hypoxia in chronic bronchitis. Chest 94: 772-778.

47. Stenmark KR, Fagan KA, Frid MG (2006) Hypoxia-induced pulmonary vascular remodeling: Cellular and molecular mechanisms. Circ Res 99: 675-691.

48. Voelkel NF, Mizuno S, Bogaard HJ (2013) The role of hypoxia in pulmonary vascular diseases: a perspective. Am J Physiol Lung Cell Mol Physiol 304: L457-L465.

49. Nakamura A, Kasamatsu N, Hashizume I, Shirai T, Hanzawa S, et al. (2000) Effects of hemoglobin on pulmonary arterial pressure and pulmonary vascular resistance in patients with chronic emphysema. Respiration 67: 502-506.

50. Azarov I, Huang KT, Basu S, Gladwin MT, Hogg N, et al. (2005) Nitric oxide scavenging by red blood cells as a function of hematocrit and oxygenation. Biol Chem 280: 39024-39032. 
Citation: Gulmez O (2017) Pulmonary Hypertension in Patients with Chronic Obstructive Pulmonary Disease: A Review for Definition, Epidemiology, Pathology, and Diagnosis. Gen Med (Los Angeles) 5: 293. doi:10.4172/2327-5146.1000293

Page 10 of 10

51. Presberg KW, Dincer HE (2003) Pathophysiology of pulmonary hypertension due to lung disease. Curr Opin Pulm Med 9: 131-138.

52. Ashutosh K, Mead G, Dunsky M (1983) Early effects of oxygen administration and prognosis in chronic obstructive pulmonary disease and cor pulmonale. Am Rev Respir Dis 127: 399-404.

53. Peinado VI, Barbera JA, Ramirez J, Gomez FP, Roca J, et al. (1998) Endothelial dysfunction in pulmonary arteries of patients with mild COPD. Am J Physiol 274: L908-913.

54. Barbera JA, Riverola A, Roca J, Ramirez J, Wagner PD, et al. (1994) Pulmonary vascular abnormalities and ventilation-perfusion relationships in mild chronic obstructive pulmonary disease. Am J Respir Crit Care Med 149: 423-429.

55. Wright JL, Churg A (2002) Animal models of cigarette smoke-induced COPD. Chest 122: 301S-306S.

56. Haddad F, Doyle R, Murphy DJ, Hunt SA (2008) Right ventricular function in cardiovascular disease, part II: Pathophysiology, clinical importance, and management of right ventricular failure. Circulation 117: 1717-1731.

57. Missov ED, De Marco T (2000) Cor Pulmonale. Curr Treat Options Cardiovasc Med 2: 149-158.

58. Vonk Noordegraaf A, Marcus JT, Roseboom B (1997) The effect of right ventricular hypertrophy on left ventricular ejection fraction in pulmonary emphysema. Chest 112: 640-645.

59. Vizza CD, Lynch JP, Ochoa LL, Richardson G, Trulock EP (1998) Right and left ventricular dysfunction in patients with severe pulmonary disease. Chest 113: 576-583.
60. Kiral N (2010) Chronic obstructive pulmonary disease and pulmonary hypertension. Solunum dergisi 12: 101-111.

61. Kessler R, Faller M, Weitzenblum E, Chaouat A, Aykut A, et al. (2001) "Natural history" of pulmonary hypertension in a series of 131 patients with chronic obstructive lung disease. Am J Respir Crit Care Med 164: 219-224.

62. Yetkin O, KarabiyikoÄŸlu G (2004) Evaluation of spirometric and pulmonary haemodynamic parameters in patients with COPD. Tuberk Toraks 52: 159-163.

63. Feigenbaum H, Armstrong WF, Ryan T (2005) Left atrium, right atrium and right ventricle. In: Feigenbaum $\mathrm{H}$, ed. Feigenbaum's echocardiography. Philadelphia, PA: Lippincott Williams and Wilkins 181-213.

64. Rudski LG, Lai WW, Afilalo J, Hua L, Handschumacher MD, et al. (2010) Guidelines for the echocardiographic assessment of the right heart in adults: A report from the American Society of Echocardiography endorsed by the European Association of Echocardiography, a registered branch of the European Society of Cardiology, and the Canadian Society of Echocardiography. J Am Soc Echocardiogr 23: 685-713.

65. Abroug F, Ouanes-Besbes L, Nciri N, Sellami N, Addad F, et al. (2006) Association of left-heart dysfunction with severe exacerbation of chronic obstructive pulmonary disease: Diagnostic performance of cardiac biomarkers. Am J Respir Crit Care Med 174: 990-996. 